\title{
Surface Strain Measurement of Thermally Sprayed Ceramics Coatings under Static and Cyclic Loadings and Its Application to Detection of Delamination*1
}

\author{
Yoshiko Shinhara $^{1}$, Rongguang Wang ${ }^{1}$, Tarou Tokuda ${ }^{1}$, Mitsuo Kido ${ }^{1}$, \\ Yoshio Harada ${ }^{2}$ and Shinji Wada ${ }^{1, * 2}$ \\ ${ }^{1}$ Department of Mechanical Systems Engineering, Faculty of Technology, Hiroshima Institute \\ of Technology, Hiroshima 731-5193, Japan \\ ${ }^{2}$ Thermal Spraying Technology R\&D Laboratories, Tocalo Co., Ltd., Akashi 674-0093, Japan
}

Thermally sprayed ceramic coatings are commonly used as thermal barriers at high temperature. However, delamination of the coating from substrate (base metal) under various operation conditions, including high temperature and mechanical loads, always leads to serious degradation of the heat shielding effect. It is important to detect the delamination in situ and nondestructively for the maintenance and management of mechanical structures. However, until now, neither a clear definition of the delamination of the coating from the substrate nor an effective method to detect and evaluate the delamination process has been proposed. In this work, the surface strains of a substrate and a thermally sprayed coating were measured using an electronic speckle interferometry (ESPI) method. As a result, generation of delamination of the coating corresponded well to the critical strain $\varepsilon_{\mathrm{c}}$ on the $\varepsilon-\sigma_{\mathrm{s}}$ curve under a static load, where a large drop in the strain occurred for the coated specimen compared to the substrate only specimen. Furthermore, generation of the delamination under a cyclic load also corresponded well to a large drop in strain for the coated specimen compared to the substrate only specimen. [doi:10.2320/matertrans.48.769]

(Received October 6, 2006; Accepted January 30, 2007; Published March 25, 2007)

Keywords: thermally sprayed ceramic coating, delamination generation, electronic speckle pattern interferometry (ESPI), surface strain, static tensile load, cyclic load

\section{Introduction}

Thermally sprayed ceramic coatings are commonly used as thermal barrier coatings (TBCs) because of their excellent heat insulating capability. ${ }^{1)}$ However, delamination of the coating from the substrate at high temperature and mechanical loads always results in damage to the substrate after loss of the thermal barrier effect. From the standpoint of material design and field application of thermally sprayed ceramic coating, it is important to clarify the delamination behavior and detect the generation of delamination of the sprayed coating.

The deformation of material surfaces is usually measured by a paste-type strain gauge on the surface. However, this method is difficult to apply at high temperatures. Instead, the authors reported several results of surface strain measurement of alumina ceramic coatings using an electronic speckle pattern interferometry (ESPI) method. ${ }^{2-5}$ It was found that the surface strain of the sprayed coating is closely related to the generation and propagation of cracks in the sprayed coating and to the delamination of the sprayed coating from the substrate ${ }^{6-9)}$ Because deformation of the sprayed coating is related to that of the substrate, it is necessary to know their individual deformation behaviors to better understand the delamination behavior of the coating. However, there are few reports that address the definition of the delamination of ceramic coatings.

In this work, the deformation of a base substrate of SUS304 steel and a ceramics coating on the substrate was

\footnotetext{
*1 This Paper was Originally Published in Japanese in J. Japan Thermal Spraying Soc. 43 (2006) 73-78.

${ }^{* 2}$ Graduate Student, Hiroshima Institute of Technology
}

measured by the ESPI method under static and cyclic loads. Then, the delamination behavior of the sprayed coating was investigated and a novel method proposed for comparing the two surface strains of the substrate and the coated specimen.

\section{Experimental Procedures}

\subsection{Specimen}

Solution-treated SUS304 steel plate (C: $0.05 \%$, Si: $1.00 \%$, Mn: $2.00 \%$, P: $0.045 \%$, S: $0.030 \%$, Cr: $18.00 \%$, Ni: $8.00 \%$; $\sigma_{0.2}: 299 \mathrm{MPa}$ ) was used as substrate material. The shape and size of the substrate specimen is shown in Fig. 1. A central circular hole was processed to introduce stress concentration. This specimen was used as the "substrate only". After the

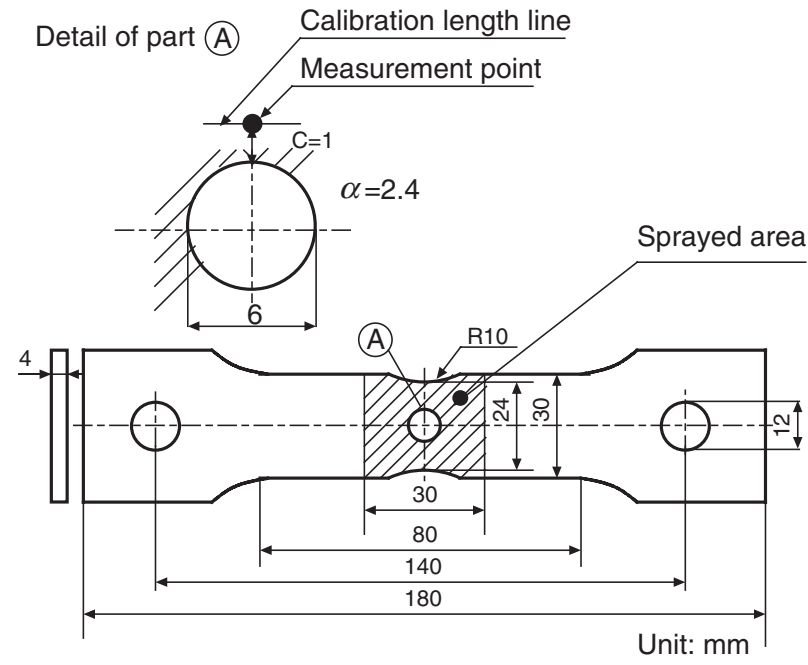

Fig. 1 Specimen shape and measurement location of surface strain. 
Table 1 Atmospheric plasma spraying conditions.

\begin{tabular}{lcc}
\hline & $\begin{array}{c}\mathrm{Al}_{2} \mathrm{O}_{3} \text { ceramics } \\
\text { coating }\end{array}$ & NiCr coating \\
\hline Chemical composition $($ wt. $\%)$ & $99.8 \% \mathrm{Al}_{2} \mathrm{O}_{3}$ & $80 \% \mathrm{Ni}, 20 \% \mathrm{Cr}$ \\
Grain size $(\mu \mathrm{m})$ & 20.7 & 70.8 \\
Arc current $(\mathrm{A})$ & 450 & 400 \\
Arc voltage $(\mathrm{V})$ & 45 & 30 \\
Gas $\quad \mathrm{Ar}(l / \mathrm{min})$ & 15 & 20 \\
Se $(l / \mathrm{min})$ & 5 & - \\
Coating thickness $(\mu \mathrm{m})$ & 100 & 100 \\
\hline
\end{tabular}

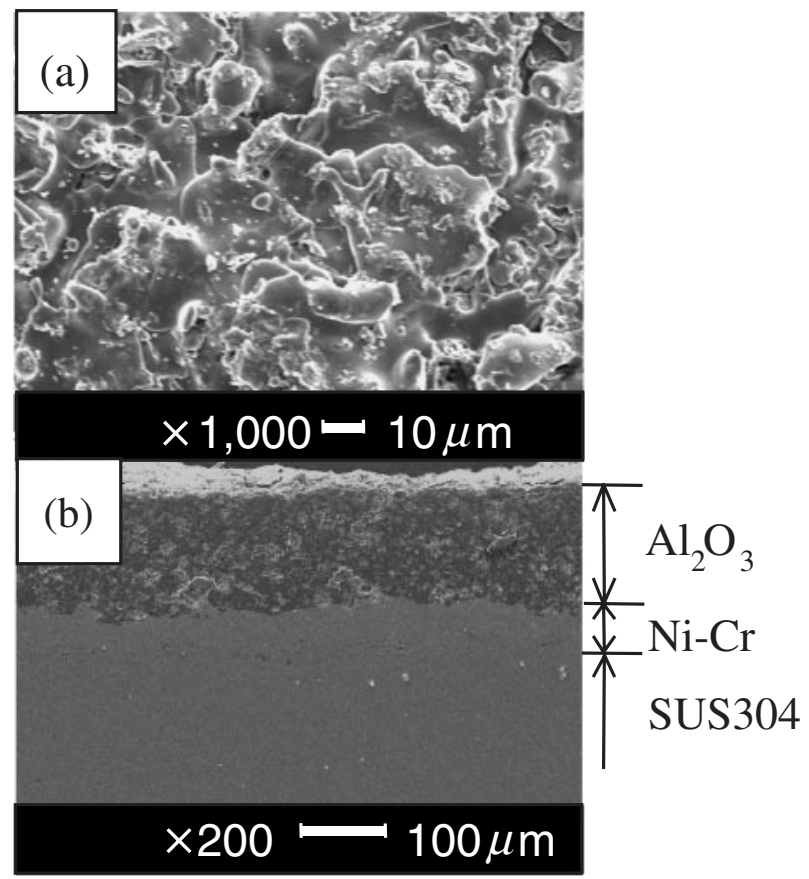

Fig. 2 The surface (a) and cross-section (b) morphologies of the coating with SEM.

substrate specimen was blasted by accelerated alumina particles (WA\#36) on the hatching area and pre-heated at $473 \mathrm{~K}$ for $480 \mathrm{~s}$, a metallic bond-coat $(\mathrm{Ni} 80 \% \mathrm{Cr} 20 \%$; grain size: $70.8 \mu \mathrm{m})$ and a ceramic topcoat $\left(\mathrm{Al}_{2} \mathrm{O}_{3}\right.$; grain size: $20.7 \mu \mathrm{m})$ were thermally sprayed using an atmospheric plasma spraying apparatus (TECHNOSERVE CO. Ltd.) on the hatching area. Such specimens with thermally sprayed coating were used as "coated specimen" in the following. The spraying conditions are shown in Table 1. The surface and the cross-section of the coated specimen are shown in Fig. 2. The porosity of the top coat was obtained from thearearatio of open pores on the observation zone by SEM. The porosity in the ceramics topcoat was about $22.5 \%$.

\subsection{Static tensile test and cyclic fatigue test}

A static tensile test was carried out at room temperature $(T=298 \mathrm{~K})$ and high temperature $(T=873 \mathrm{~K})$ using an autograph testing machine (Shimadzu Co.: AG-250KND). Two tensile rates of $T_{\mathrm{s}}=0.8 \times 10^{-6}$ and $1.7 \times 10^{-6} \mathrm{~m} / \mathrm{s}$ were used. Cyclic fatigue tests were carried out using a servohydraulic fatigue testing machine (Shimadzu Co.: EHFEG50KN-20L) at $T=298 \mathrm{~K}$ and $873 \mathrm{~K}$. In the cyclic test, the stress ratio $(R)$ was 0 ; the nominal stress $\left(\sigma_{\max }\right.$ : at the specimen center) was $120,175,180$ or $300 \mathrm{MPa}$; the frequency $(f)$ was $14 \mathrm{~Hz}$; and the load was sinusoidally cycled. Specimens were heated with an induction heating system (Oyo Electic Co.: MT-5KD-C) and the temperatures were measured with a radiation thermometer (Minolta Camera Co. Ltd: IR-308).

\subsection{ESPI method}

The surface strains (longitudinal strain) of the substrate only and the coated specimen were measured by an ESPI system (Dr. ETTEMEYER GmbH \& Co.: Q-300). The measurement area was $9.0 \times 10^{2} \mathrm{~mm}^{2}$ at room temperature and $2.4 \times 10^{2} \mathrm{~mm}^{2}$ at high temperature. The measurement area at high temperature was smaller than that room temperature, because a coil type induction heater was used. In the static tensile test, the surface speckle of the specimen was recorded using a CCD camera for each load increment of 13.8 MPa. In the cyclic fatigue test, after a certain number of cycles the specimen was unloaded and the surface speckle of the specimen was recorded when the specimen was reloaded at the static tensile mode until the load reached the maximum stress of $\sigma_{\max }$. The data processing from the recorded speckles to the surface displacement and the surface strain was carried out by an equal interval method ${ }^{5)}$ using an ISTRA data system (Dr. ETTEMEYER GmbH \& Co.).

In this work, after the measurement of the surface strains on the substrate only and the coated specimen under the static monotonic increased load (nominal tensile stress) and the cyclic sinusoidal load (nominal cyclic stress), the coating was checked for generation of delamination by SEM observation of the cross-section and compared with the obtained $\varepsilon-\sigma_{\mathrm{s}}$ curve under static load and the $\varepsilon_{\max }-N$ curve under cyclic load.

\section{Results and Discussion}

\subsection{Surface strain measurement by ESPI}

The thickness of the coating (about $200 \mu \mathrm{m}$ ) is much thinner than the substrate (about $4 \mathrm{~mm}$ ), thus the crosssection area for the two specimens is almost the same. A paste-type strain gauge was used to measure the surface strain of two specimens under a static increased load at room temperature. ${ }^{6)}$ As a result, the strain values for each specimen were almost the same when the applied stress was small. ${ }^{6}$ It means that the deformation of the sprayed coating almost follows that of the substrate.

The surface strains were measured by the ESPI method that is also able to measure at high temperature. One strain distribution on the specimen surface is shown in Fig. 3. The color varied from black to red as the strain value increased. It is clear that strain concentration zones appeared near the circle hole for each specimen under a tensile load.

\subsection{Change of surface strain under static tensile load}

Figure 4 shows the $\varepsilon-\sigma_{\mathrm{s}}$ curves of specimens at $T=298 \mathrm{~K}$ and $873 \mathrm{~K}$ at load rates of $T_{\mathrm{s}}=0.8 \times 10^{-6}$ and $1.7 \times 10^{-6} \mathrm{~m} / \mathrm{s}$. The surface strain was measured by the ESPI method ${ }^{6,7)}$ at a position $1 \mathrm{~mm}$ from the edge of the circle hole (see Fig. 1; detail of part A, mark), and the calibration 


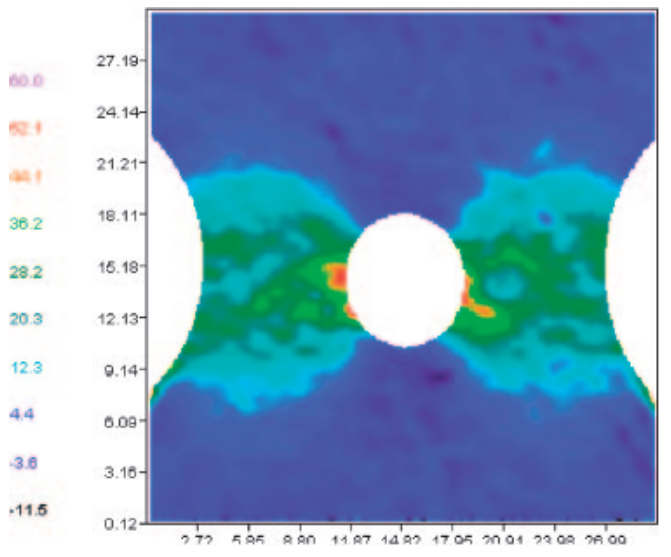

(a) non-coating

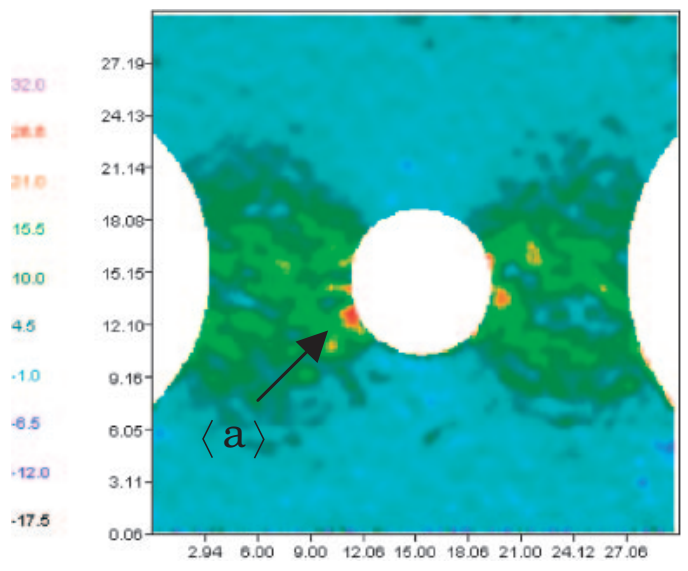

(b) coating

Fig. 3 Strain distribution on coating and non-coating surface $\left(T_{\mathrm{s}}=1.7 \times 10^{-6} \mathrm{~m} / \mathrm{s}, T=298 \mathrm{~K}\right)$.

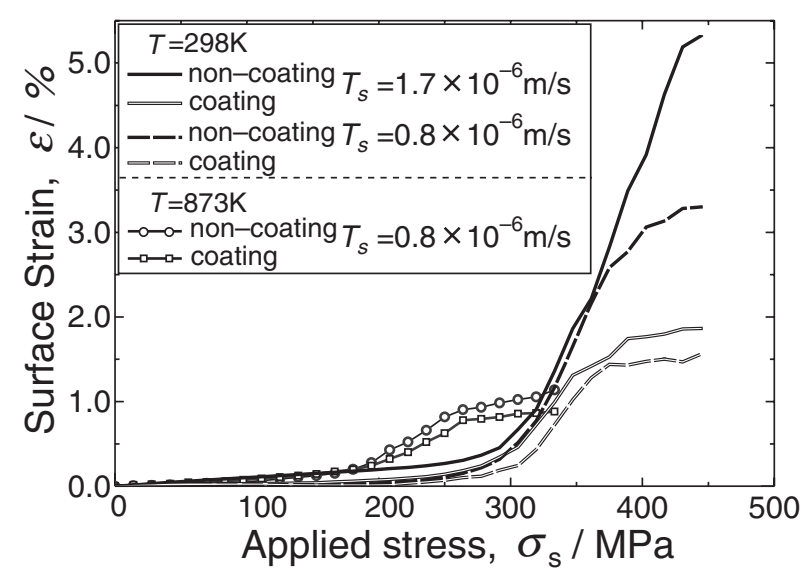

Fig. 4 Stress-strain curve of coating and non-coating $\left(T=298 \mathrm{~K}, T_{\mathrm{s}}=\right.$ $\left.1.7 \times 10^{-6}, 0.8 \times 10^{-6} \mathrm{~m} / \mathrm{s}, T=873 \mathrm{~K}, T_{\mathrm{s}}=0.8 \times 10^{-6} \mathrm{~m} / \mathrm{s}\right)$.

length (see Fig. 1) was $5 \mathrm{~mm} .{ }^{6,7)}$ The displacements of the two end points of the calibration length line was used for the calculation of surface strain. Each curve was averaged from 3 measurements. It had been reported that the surface strains on same specimen measured by a paste-type strain gauge and the ESPI method was almost the same at a calibration length of $5 \mathrm{~mm} .{ }^{6}$ ) According to Fig. 4, there are no remarkable differences between the two types of specimens until the stress reached a specific value. The value was different for different load rates and different temperatures. However, when the stress level became larger than this value, the surface strain of the coated specimen became smaller than that of substrate only. This result is similar to the result of Muramatsu et al. ${ }^{10)}$ that was discussed about the delamination of coating and the traceability of strain in coating versus substrate.

Figure 5 shows a schematic drawing of the $\varepsilon-\sigma_{\mathrm{s}}$ curve originated from Fig. 4. Firstly, the strains of the two types of specimens increase at the same speed and have almost the same value until the tensile stress reaches a specific stress level (tiny strain zone of $\varepsilon_{\mathrm{I}}$ ). Next, the strain of the two specimens becomes different even though their rate of increase of strain is almost the same as with the increase of

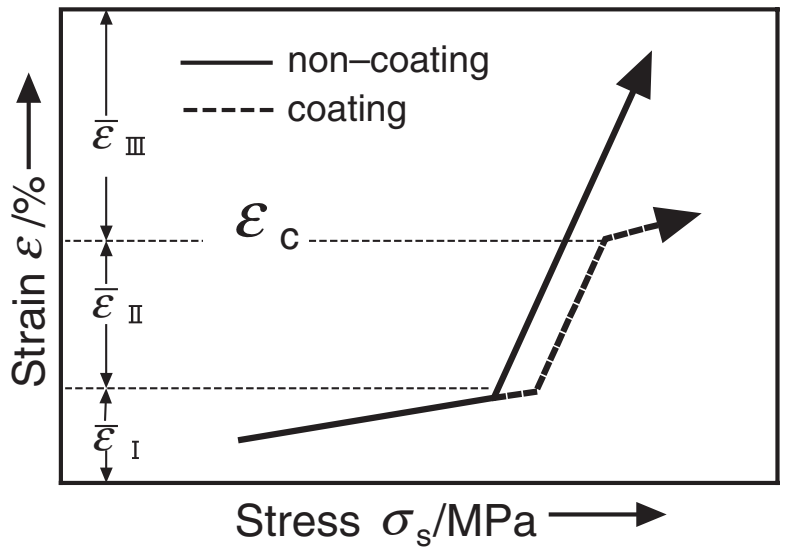

Fig. 5 Stress-strain curve of coating and non-coating.

tensile stress (zone of $\varepsilon_{\mathrm{II}}$ ). Finally, both strains and their increase rates with increased tensile stress are different (zone of $\varepsilon_{\mathrm{III}}$ ). The strain with a sudden change from $\varepsilon_{\mathrm{II}}$ to $\varepsilon_{\mathrm{III}}$, i.e., the break point of $\varepsilon-\sigma_{\mathrm{s}}$ curve for the coated specimen, is defined as the static critical strain $\varepsilon_{\mathrm{c}}$.

To better understand the reason for the appearance of the break point of $\varepsilon_{\mathrm{c}}$ on the $\varepsilon-\sigma_{\mathrm{s}}$ curve of the coated specimen, the cross-section of the coated specimens near the central hole was observed after they were loaded with a stress near $\varepsilon_{\mathrm{c}}$ of about $360 \mathrm{MPa}$ at $T=298 \mathrm{~K}$ and $T_{\mathrm{s}}=1.7 \times 10^{-6} \mathrm{~m} / \mathrm{s}$. One characteristic result is shown in Fig. 6. At least 3 specimens were used for the observation for each loading condition. No cracks can be observed in $\sigma_{\mathrm{s}} \approx 333 \mathrm{MPa}$ (Fig. 6(A)). Vertical cracks with a length of about $100 \mu \mathrm{m}$ (half of the coating thickness) and horizontal cracks propagated from the vertical cracks between the coating/ substrate interface were observed after the specimen was loaded to $\sigma_{\mathrm{s}} \approx 347 \mathrm{MPa}$ (Fig. 6(B)). For $\sigma_{\mathrm{s}} \approx 361 \mathrm{MPa}$, horizontal cracks with a length of about $400 \mu \mathrm{m} \sim 1 \mathrm{~mm}$ were observed (Fig. 6(C)). After the stress was over $\varepsilon_{\mathrm{c}}$, the rate of strain increase decreased (Fig. 5) and the horizontal cracks became longer (Fig. 6(D)). Accordingly, although the coating deforms almost following the substrate in the $\varepsilon_{\mathrm{I}} \sim \varepsilon_{\mathrm{II}}$ zone, it can not follow well with the substrate when the 


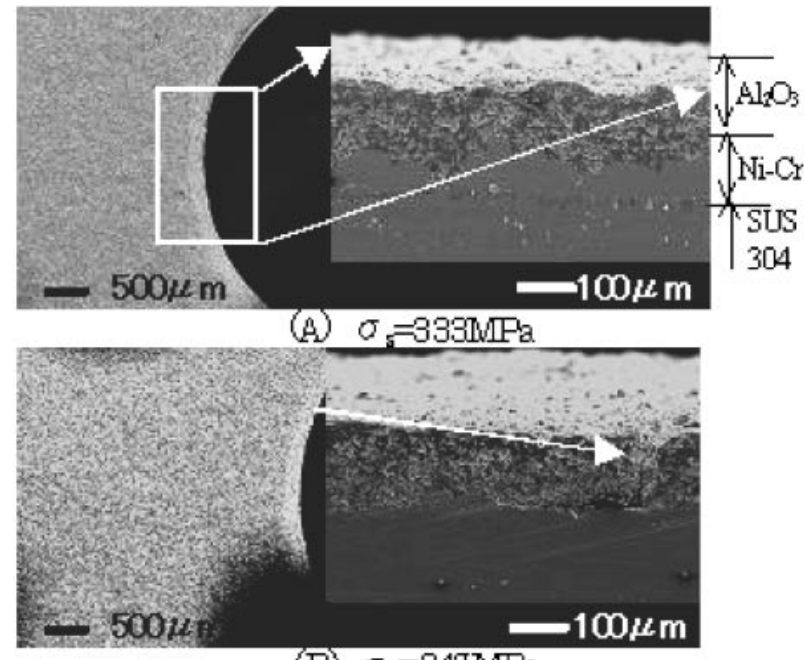

(B) $\sigma_{\mathrm{s}}=347 \mathrm{MPa}$

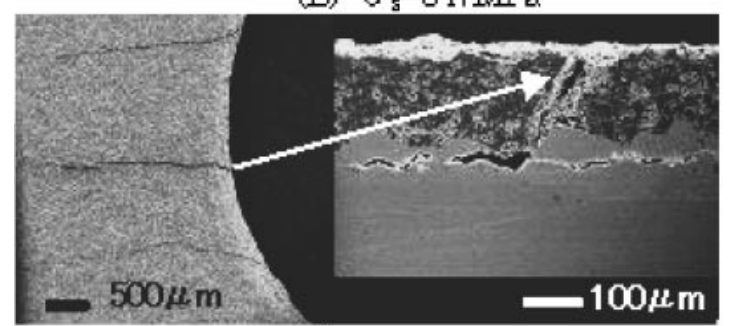

(C) $\sigma_{\mathrm{s}}=361 \mathrm{MPa}$

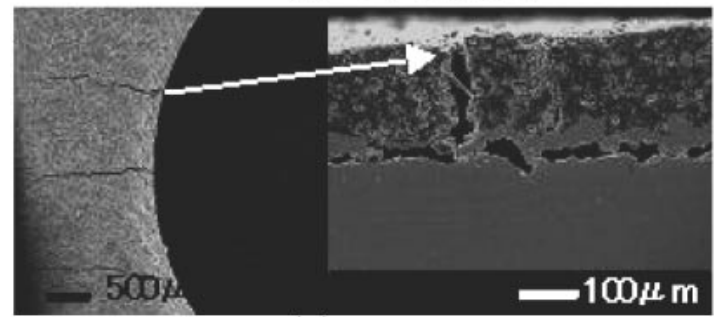

(D) $\sigma_{\mathrm{s}}=37 \mathrm{GMPa}$

Fig. 6 Cross-section morphologies of coating after applied stress $\left(T_{\mathrm{s}}=\right.$ $\left.1.7 \times 10^{-6} \mathrm{~m} / \mathrm{s}, T=298 \mathrm{~K}\right)$.

deformation of substrate become larger and vertical cracks propagate in the coating with holes and microcracks. The limit of nondestructive deformation is usually quite small for ceramic sprayed coatings. ${ }^{11)}$ Furthermore, the vertical cracks changed their direction to induce horizontal cracks (delamination) due to shear stress, thus decreasing the surface strain of the coating.

The effect of calibration length on the calculation of the surface strain was also investigated by comparing lengths of $0.2 \mathrm{~mm}$ (see Fig. 3(b); part $\langle\mathrm{a}\rangle$ ) and $5 \mathrm{~mm}$. As a result, the value of $\varepsilon_{\mathrm{c}}$ did not change with calibration length. All the data was processed at a calibration length of $5 \mathrm{~mm}$ in the following descriptions.

The value of $\varepsilon_{\mathrm{c}}$ and the appearance of cracks were checked at different tensile rates and temperatures (Fig. 4). The surface strains for both the substrate only and the coated specimens were a little larger for $T_{\mathrm{s}}=1.7 \times 10^{-6} \mathrm{~m} / \mathrm{s}$ than $T_{\mathrm{s}}=0.8 \times 10^{-6} \mathrm{~m} / \mathrm{s}$. The change in the coated specimen might be due to the work hardening effect in substrate. ${ }^{12)}$ For each tensile rate, vertical and horizontal cracks were observed when the stress was greater than $\varepsilon_{\mathrm{c}}$. Next, the surface strain of the substrate only and the coated specimen at

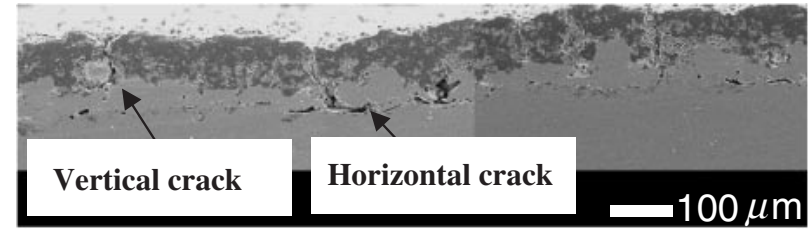

(A) $\sigma_{\mathrm{s}}=200 \mathrm{MPa}$

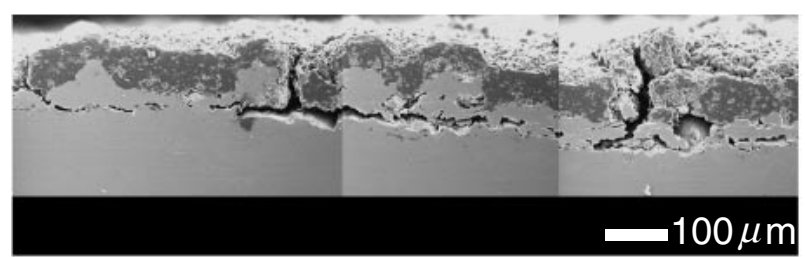

(B) $\sigma_{\mathrm{s}}=230 \mathrm{MPa}$

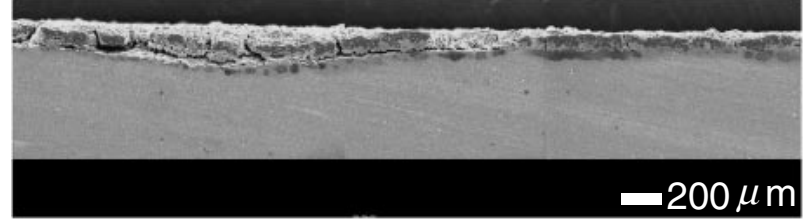

(C) $\sigma_{\mathrm{s}}=290 \mathrm{MPa}$

Fig. 7 Cross-section morphologies of coating after applied stress $\left(T_{\mathrm{s}}=\right.$ $\left.0.8 \times 10^{-6} \mathrm{~m} / \mathrm{s}, T=873 \mathrm{~K}\right)$.

$T=873 \mathrm{~K}$ were almost the same in the $\varepsilon_{\mathrm{I}}$ zone, similar to that seen at $T=298 \mathrm{~K}$. However, the static critical strain $\varepsilon_{\mathrm{c}}$ was smaller at about $200 \mathrm{MPa}$, less than that at $T=298 \mathrm{~K}$ (about $360 \mathrm{MPa}$ ). At a stress level of $200 \mathrm{MPa}$, the strain of the coated specimen was smaller than that of the substrate. Cross-sections of the coated specimen at $\sigma_{\mathrm{s}} \approx 200,230$ and $290 \mathrm{MPa}$ were observed (Fig. 7(A-C)). Similar to that at $T=298 \mathrm{~K}$, vertical cracks were observed at the topcoat and changed their direction to horizontal cracks. Notably, the change of the direction of cracks from vertical to horizontal occurred at a lower stress level than that at $T=298 \mathrm{~K}$. Thus, the stress corresponding to $\varepsilon_{\mathrm{c}}$ changed markedly with temperature. This is likely due to the greater slip deformation of the substrate at high temperature and to the appearance of large strain even under a small stress. Thus, the deformation of the coating cannot follow the deformation of substrate, resulting in the earlier appearance of both vertical and horizontal cracks.

In general, the vertical cracks originate from defects in the sprayed coating despite differences in tensile rates and temperatures. The cracks change from vertical to horizontal relative to the substrate when the cracks propagate along the coating/substrate interface. However, the propagation of the vertical crack to a horizontal crack happens gradually. ${ }^{13-15)}$ As described above, delamination of the coating from the substrate can be defined by the length of the horizontal crack in relation to the critical strain of $\varepsilon_{\mathrm{c}}$. This is because, when the surface strain reaches $\varepsilon_{\mathrm{c}}$, the length of the vertical crack is slightly more than half of the coating thickness or the total length of the vertical and horizontal cracks is nearly equal to the thickness of the coating. Of course it is still difficult for the ESPI method to detect whether delamination of coating has occurred at the point of measurement. For the foreseeable future, it is advisable to use the in situ method of acoustic emission (AE) and the ESPI method, and to compare the results. 

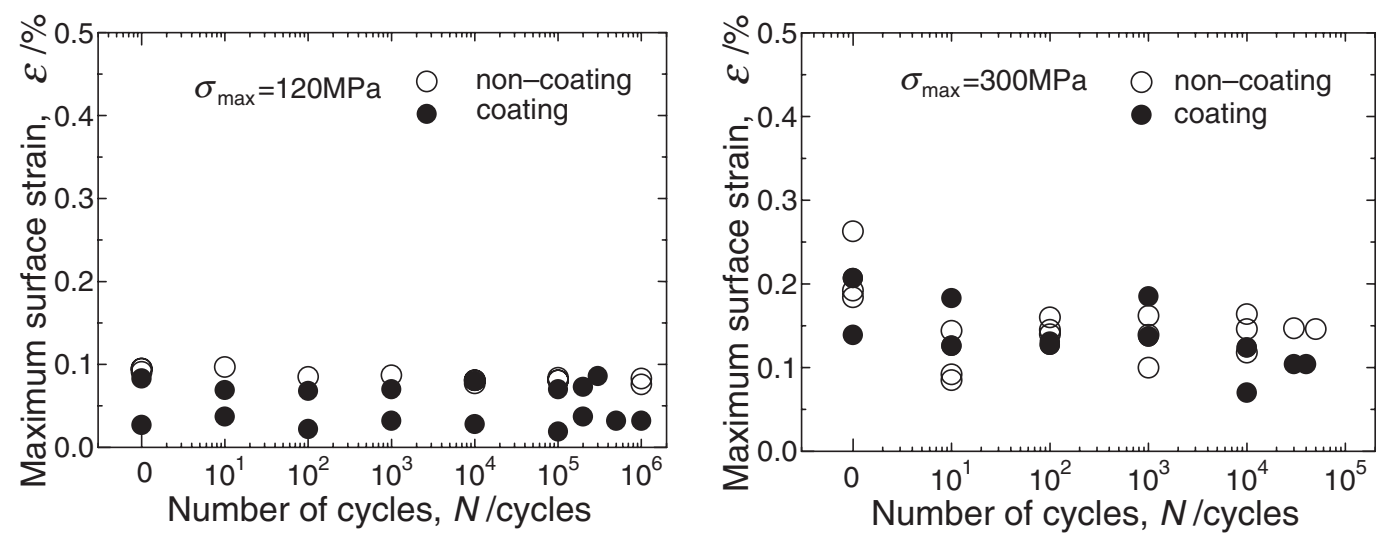

Fig. 8 Surface strain-number of cycles curve on coating and non-coating $(R=0, f=14 \mathrm{~Hz}, T=298 \mathrm{~K})$.

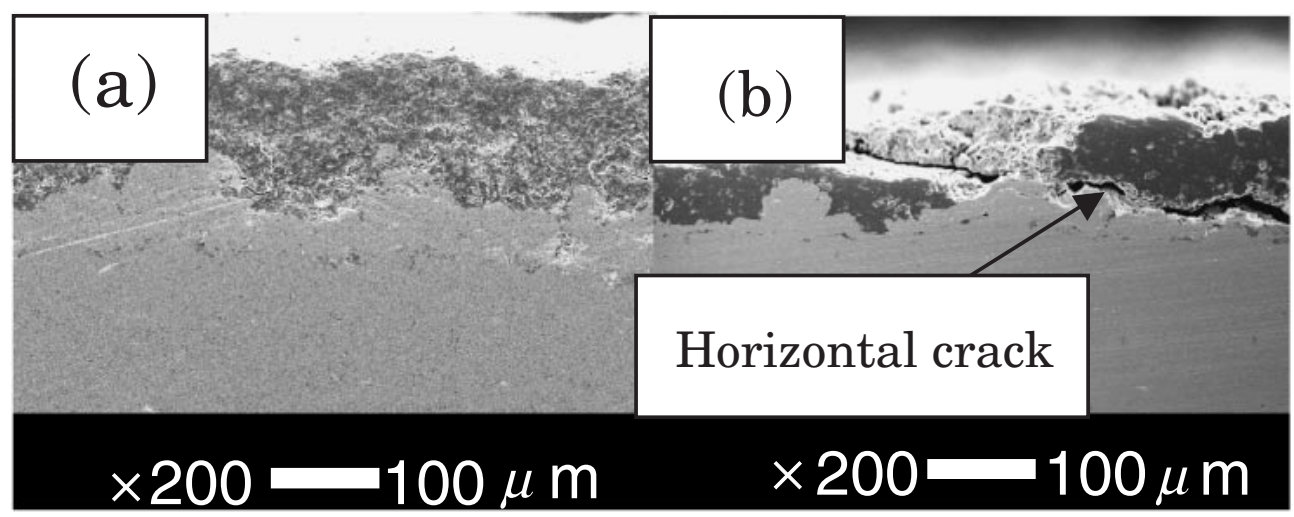

Fig. 9 Cross-section morphologies of coating after fatigue test $\left(R=0, f=14 \mathrm{~Hz}, T=298 \mathrm{~K},(\mathrm{a}) \sigma_{\max }=120 \mathrm{MPa}, N=1 \times 10^{6}\right.$ cycles, (b) $\sigma_{\max }=300 \mathrm{MPa}, N=1 \times 10^{4}$ cycles).

\subsection{Change of surface strain under cyclic load}

Figure 8 shows the relation between the maximum surface strain during each loading cycle and the number of cycles when applying the cyclic loads between $\sigma_{\min }=0$ and $\sigma_{\max }=$ $120 \mathrm{MPa}$ (stress ratio $\sigma_{\min } / \sigma_{\max }=0$ ), and $\sigma_{\min }=0$ and $\sigma_{\max }=300 \mathrm{MPa}$ at $T=298 \mathrm{~K}$ with a frequency of $f=$ $14 \mathrm{~Hz}$. At low stress $\left(\sigma_{\max }=120 \mathrm{MPa}\right)$, no significant difference between the substrate only and the coated specimen was found. No cracks were found from the cross-section observation after $N=1 \times 10^{6}$ cycles (Fig. 9(a)). At high stress $\left(\sigma_{\max }=300 \mathrm{MPa}\right)$, the surface strain changed largely for both specimens; in particular, a relatively large drop in strain appeared on the coated specimen after $N=1 \times 10^{4}$ cycles compared to substrate only. According to the crosssection observation (Fig. 9(b)), vertical and horizontal cracks (delamination) along the interface were found after $N=$ $1 \times 10^{4}$ cycles. The same measurement at $T=873 \mathrm{~K}$ was also carried out when applying the cyclic load between $\sigma_{\text {min }}=0$ and $\sigma_{\max }=120 \mathrm{MPa}$, and $\sigma_{\min }=0$ and $\sigma_{\max }=$ $175 \sim 180 \mathrm{MPa}$. At low stress $\left(\sigma_{\max }=120 \mathrm{MPa}\right)$, similar to that seen at $T=298 \mathrm{~K}$, no remarkable difference was found between the two specimens. On the other hand, at high stress $\left(\sigma_{\max }=175 \sim 180 \mathrm{MPa}\right)$, the value and change in surface strain for the coated specimen was much different from that of substrate only with increasing number of cycles; their values were different until $N=10$ cycles and the difference disappeared thereafter. According to the cross-section ob- servation, vertical cracks occurred after 1 cycle of loading, and many horizontal cracks were observed after $N=1 \times$ $10^{5}$ cycles.

Deformation martensitic transformation and plastic slip occur near the central hole on austenite stainless steel with linear increases in load. ${ }^{16}$ ) This could be one reason for the change in the surface strain of the substrate at room temperature. In fact, the Vickers hardness near the notch of the substrate after $N=1 \times 10^{4}$ cylces at loads of $\sigma_{\max }=210$ and $300 \mathrm{MPa}$ were measured. The value was about $H \mathrm{v} \fallingdotseq 171$ at $\sigma_{\max }=210 \mathrm{MPa}$ and about $H \mathrm{v} \fallingdotseq 183$ at $\sigma_{\max }=300 \mathrm{MPa}$, showing higher hardness at higher stress levels. Although strain generally increases with plastic deformation, a reversed plastic zone (RPZ zone) might appear after the stress is unloaded in the cyclic load test. ${ }^{17)}$ The strain value might become small decrease due to the influence of the RPZ zone when it was reloaded. Accordingly, the cyclic work-hardening and the formation of the RZP zone could result in change of surface strain. On the other hand, since the sprayed coating is much thinner than the substrate, the surface strain of the coating nearly follows the substrate under low stress. However, the stress concentration will be much larger due to the existence of defects in the coating, vertical cracks and delamination. Furthermore, the formation of the RPZ zones during cyclic loading in the substrate will result in irregular, or non-linear, deformation. Also, slip deformation may be much larger at high temperatures. ${ }^{18)}$ Accordingly, both the 
sum and the length of cracks in the coating increase and result in horizontal cracks or delamination. Furthermore, a residual stress (strain) exists due to the mismatch between the coating and the substrate due to different thermal coefficients of expansion, ${ }^{19)}$ which also promotes the generation of cracks and delamination. Accordingly, when the delamination occurs after only several limited cycles at high temperature, the change of surface strain become small. At the initial stage of applying high stress levels $\left(\sigma_{\max }=175 \sim 180 \mathrm{MPa}\right)$ at high temperature, deformation of the coating cannot follow that of the substrate, resulting in the generation of cracks and delamination. Accordingly, the delamination behavior of the sprayed coating is almost the same for static or cyclic loads. In other words, the generation of delamination of the coating can also be confirmed by detecting the change in surface strain of the coated specimen compared to that of substrate only.

\section{Conclusions}

The surface strain of SUS304 stainless steel substrate and the thermally sprayed coated specimen were measured by the ESPI method under static and cyclic loads. The delamination of the thermally sprayed coating was investigated, and the values of strain on the sprayed coating and substrate only specimens are discussed. The results are summarized as follows:

(1) In the static tensile test, the surface strain of the coating was almost the same as that of the substrate at the low stress levels. However, when the delamination occurred along the coating/substrate interface, the surface strain of the coated specimen was less than that of the substrate only specimen. It is possible to define a critical strain $\varepsilon_{\mathrm{c}}$ on the $\varepsilon-\sigma_{\mathrm{s}}$ curve by comparing the strain change of the coated specimen and the substrate only specimen, which corresponds to the degree of delamination of the coating.

(2) Vertical cracks generally originate from defects in the sprayed coating despite different tensile rates and temperatures. The vertical cracks changed to horizontal ones to delaminate the coating from the substrate.

(3) In the cyclic tests, delamination was also confirmed by comparing the strain change of the coated specimen and the substrate.

\section{Acknowledgements}

Part of this work was supported by MEXT.HAITEKU, 2004 .

\section{REFERENCES}

1) A. Hasui: Thermal Spraying Engineering (Sanpo Publications, Inc., 1996) pp. 187-194.

2) K. S. Kim and M. Murozono: Trans. Jpn. Soc. Mech. Eng. A-60 (1994) 2567-2572.

3) A. J. Moore and J. R. Tyrer: J. Strain Analysis. 29 (1994) 257-262.

4) I. Yamaguchi: Met. Technol. 70 (2000) 862-868

5) S. Toyooka: Met. Technol. 70 (2000) 869-875.

6) M. Kido, R. Wang, S. Nakamura, M. Takeda, M. Yamasaki and T. Tokuda: J. Soc. Mater. Sci., Jpn. 51 (2002) 1417-1422.

7) R. Wang, M. Kido, G. Katayama, T. Tokuda and N. Morihiro: J. Jpn. Thermal Spray. Soc. 40 (2003) 1-8.

8) R. Wang and M. Kido: J. Nondestructive Evaluation. 21 (2003) 117126.

9) R. Wang, M. Yamazaki, T. Tokuda, Y. Shinhara, G. Katayama, M. Kido and N. Morihiro: FATIGUE 2003 (The Engineering Integrity Society, Cambridge, 2003) pp. 341-348.

10) Y. Muramatsu and S. Kuroda: J. Jpn. Weld. Soc. 20 (2002) 287-294.

11) G. Guidoni, H. Y. Torres and G. M. Anglada: Key Eng. Mater. 290 (2005) 336-339.

12) K. Kuroki, M. Omori and Y. Tomota: Strength and Fracture of Metal. (Morikita Publishing, Co., Inc., 1986) p. 105.

13) K. Akita and S. Tobe: J. Soc. Mater. Sci., Jpn. 53 (2004) 740-745.

14) H. Kisuki and M. Sugano: Yousya Gijutsu. Jpn. 22 (2003) 23-27.

15) U. Hwang, T. Ogawa and K. Tokaji: Trans. Jpn. Soc. Mech. Eng. 59-A (1993) 1663-1668.

16) H. Takei: Kinzoku Zairyou Gaku (Rikougakusha Publishing Co., Ltd., 1997) p. 139.

17) S. Suresh: Fatigue of Materials, (Cambridge University Press, 1991) pp. 162-165.

18) H. Nakazawa and H. Kobayashi: Strength of solid (Kyoritsu Shuppan Co., Ltd., 1991) p. 206.

19) M. Toyoda: Interface mechanics (Rikougakusha Publishing Co., Ltd., 1991) p. 123. 